\section{SEEDS}

Surrey Energy Economics

Discussion paper Series

\section{SURREY}

ENERGY

ECONOMICS

Centre

\title{
Efficiency and Performance in the Gas Industry
}

\author{
David Hawdon
}

January 2003

SEEDS 106

ISSN 1749-8384

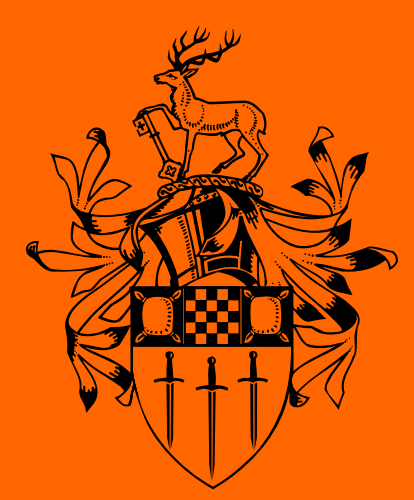

Department of Economics University of Surrey 
The Surrey Energy Economics Centre (SEEC) consists of members of the Department of Economics who work on energy economics, environmental economics and regulation. The Department of Economics has a long-standing tradition of energy economics research from its early origins under the leadership of Professor Colin Robinson. This was consolidated in 1983 when the University established SEEC, with Colin as the Director; to study the economics of energy and energy markets.

SEEC undertakes original energy economics research and since being established it has conducted research across the whole spectrum of energy economics, including the international oil market, North Sea oil \& gas, UK \& international coal, gas privatisation \& regulation, electricity privatisation \& regulation, measurement of efficiency in energy industries, energy \& development, energy demand modelling \& forecasting, and energy \& the environment.

SEEC research output includes SEEDS - Surrey Energy Economic Discussion paper Series (details at www.seec.surrey.ac.uk/Research/SEEDS.htm) as well as a range of other academic papers, books and monographs. SEEC also runs workshops and conferences that bring together academics and practitioners to explore and discuss the important energy issues of the day.

SEEC also attracts a large proportion of the department's PhD students and oversees the MSc in Energy Economics \& Policy. Many students have successfully completed their MSc and/or PhD in energy economics and gone on to very interesting and rewarding careers, both in academia and the energy industry.

Enquiries:

Director of SEEC and Editor of SEEDS:

Lester C Hunt

SEEC,

Department of Economics, University of Surrey, Guildford GU2 7XH, UK.

Tel: $\quad$ +44 (0)1483 686956

Fax: $\quad$ +44 (0)1483689548

Email: L.Hunt@surrey.ac.uk

www.seec.surrey.ac.uk 


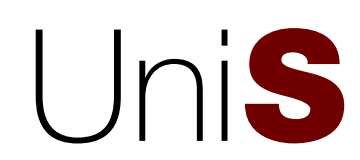

THEEC

\title{
University of Surrey
}

\section{Surrey Energy Economics Centre (SEEC) \\ Department of Economics}

\author{
SEEDS 106
}

ISSN 1749-8384

EFFICIENCY AND PERFORMANCE IN THE GAS INDUSTRY

David Hawdon

January 2003

This paper may not be quoted or reproduced without permission. 


\section{Efficiency and performance in the gas industry}

\section{David Hawdon}

\section{Introduction and outline}

Perhaps the most obvious characteristic of the gas industry is its rapid growth during recent years. Production of gas world-wide rose by almost 5\% between 1998 and 1999, with Russia, Algeria, Norway and Argentina experiencing the most rapid change (IGU, 2000a and 200b). Output of the North Sea producers (Great Britain, Norway and the Netherlands) has expanded by over 77\% during the last decade, supplying large importers such as Germany, Italy, France, Belgium and Spain. International trade has grown as consumption in the leading importers - America, Japan and Germany, and the Asian-Pacific area - has increased rapidly in recent years. These developments point to the success of gas in displacing other fuels in the energy mix, and represent not merely an economic response to relative price changes but in addition a fundamental switch in taste towards less polluting fuels. Particularly significant have been the growth in markets in power generation, co-generation, transport (sales to natural gas vehicles), cooling and dehumidification (especially in Asian markets).

On the policy front, the impact of regulatory reform has been important particularly throughout North America and Europe ${ }^{1}$. The deregulation of the electricity sector and its opening to market trading has tended to work in favour of gas as older

\footnotetext{
${ }^{1}$ Colin Robinson detected the beginnings of a Schumpeterian 'gale of creative destruction' in the UK in1994 (Robinson, 1994)
} 
less flexible power stations are phased out, and nuclear expansion slowed and in some cases reversed. Countries most recently affected here are Belgium, Canada, Finland, Germany, Hungary, the Netherlands, and, outside of Europe, in Korea.

The aim of this paper is to assess the efficiency and performance of a wide range of gas industries using recently published country level data on essential outputs and inputs. Detailed individual country studies of efficiency have been carried out before by Price and Weyman-Jones (1996) and by Kim and Lee (1995). Neither of these attempted to compare the national industry with international experience. More recently Yunos and Hawdon (1997) and Kim et al. (1999) have attempted international comparisons for electricity and gas respectively. Yunos and Hawdon focused particularly on developing countries while Kim et al. examined the performance of gas companies in North America, Europe, Japan and Korea. The analysis in this paper gives a wider coverage based on over 30 countries in order to attempt a balanced assessment of factors affecting efficiency.

\section{Gas policy developments}

Significant policy developments affecting the gas industry since the mid 1980s have included the privatization, liberalization and deregulation of national gas markets, and the reduction of trade barriers within important multinational groupings. The process commenced in the United States, was followed in the United Kingdom and currently dominates the debate over gas policy in the European Union (EU) as well as in other countries.

In the United States, reform was precipitated by the impact of falling oil prices 
during the 1980s on a market which had become locked into high price long term contracts for gas. The US Federal Energy Regulatory Commission (FERC) decision to release distributors from take-or-pay provisions in 1984 led to the stranding of many gas pipeline contracts. In 1992, pipeline companies were required to unbundle transportation, storage and open access. The resulting upsurge in competition, and development of spot markets led to significant falls in the price of gas. This makes the US experience a powerful model in favour of more competitive markets elsewhere.

The UK gas market has also liberalized significantly. Between privatization in 1986 and the passing of the 1995 Gas Act, the industry regulator, the Office for Gas and Electricity Markets (Ofgem) (and before that the Office of Gas Regulation, Ofgas) ${ }^{2}$, has sought to introduce competition into the gas market. The 1995 Act opened up the UK retail market to competition in a process which was completed by May 1998. This was followed by the commencement of gas storage auctioning in 1999, the development of new gas capacity, balancing and trading arrangements involving an On-The-DayCommodity Market (OCM ) and most recently by the auctioning of entry and exit capacity. Regulation of prices is still significant however, as indicated in discussions over Transco’s price control for the period 2002 to 2007.

Although energy, including gas, was not part of the original policy ambit of the European Union, significant intervention began in the early 1990s with the price transparency Directive of June 1990, followed in May 1991 by the Directive covering the transit of natural gas via grids. More important was the adoption on 22 June 1998 of the Directive on the interior gas market (European Commission, 1998). Although the directive took effect on 10th August 2000 various member countries had already begun 
to open their markets. Some countries (UK, Belgium, Finland, Ireland, Italy and Spain) have already implemented the directive at least in part (European Commission, 2000). Others like Austria, Denmark, France, Germany, Luxembourg, Sweden and Netherland are moving towards implementation while Greece and Portugal have still to begin the process. The effectiveness of the Directive is likely to be variable because of lack of agreement on access charging and unbundling. Most producers are reluctant to separate transportation, storage and trading activities as the UK has done. Lack of agreement on access to upstream pipeline networks could significantly slow access to cheapest sources of gas. Although the Commission anticipates that $77.9 \%$ of the 15 member market will be open by 2000, $90 \%$ by 2008 and 91.4\% 'later', a large variation in implementation (from 33\% to 100\%) is anticipated.

The development of trade in gas within Europe was already apparent from the opening of the interconnector between UK and Belgium in October 1998. The 1998 Gas Directive provides further stimulus to this process. Pipeline owners are required to give access to third parties to the extent that capacity is available. Although owners can refuse to provide access on a number of grounds including public-service obligations, or serious economic and financial difficulties with take or pay contracts, it is likely that the Directive will promote significant extra competitive pressures on operators.

\section{Distinguishing features of the gas industry}

In seeking to understand developments in the gas industry, it is important to recognise some special feature of the gas industry (Newbery, 2000). These include

\footnotetext{
${ }^{2}$ Ofgem is an amalgamation of Ofgas and Offer.
} 
$\checkmark \quad$ Opaque and ill defined costs.

$\checkmark \quad$ Production determined by geology which influences exploration, production and pipeline investment and operating costs.

$\checkmark \quad$ Producers' preferences for guaranteed markets/long term contracts/ high prices to recover investment costs together with a tendency to desire vertical integration.

$\checkmark$ Consumer preference for long term security of supply.

All of the above factors constitute barriers against efficiency improvements in the gas industry. That European countries have been able to overcome some of these barriers is due to a unique set of circumstances including the expansion of offshore supplies in Europe, the availability of gas from Russia following the collapse of its domestic economy post cold war, the extension of international pipeline systems, investment in Liquid National Gas (LNG) terminals to ensure diversity of supply sources, removal of discriminatory access to third party pipeline networks, and the opening of the electricity market to gas. One of the purposes of this paper is to establish whether these conditions have led to improved levels of efficiency.

\section{Measuring the efficiency of the gas industry}

The efficiency literature distinguishes between technical and allocative efficiency (Fare et al., 1994). Technical efficiency concerns the relationship between inputs and outputs such that a firm is efficient if it achieves maximum output for given inputs or minimum input utilization for given outputs. Allocative efficiency assumes technical efficiency, and compares alternative positions in terms of relative prices, either of inputs or 
outputs. In attempting to measure the efficiency of the gas industries of various countries gas consumption or sales are used as a measure of output. This ensures the focus is on the downstream element of the gas industry which handles imported as well as domestically produced gas. Gas production (the upstream part of the industry) has a very different structure to the publicly owned or regulated downstream industry and it is that latter part which is of interest. Gas production is carried out by a mixture of oil and gas companies often large multinational oil producers. The analysis is confined to gas from its entry into the bulk transmission system, through the local distribution networks to the final consumer.

An important feature of this part of the gas industry is that it is multiproduct in that gas is supplied under different conditions to different types of consumers. Household, industrial, commercial and power station customers have very different load and other characteristics, and can be supplied on either continuous or interruptible bases. At the same time, availability of gas is important to consumers. Finally, regulatory authorities prefer that industries supply as many potential customers as possible. Thus at a minimum, sales and numbers of customers should be taken as separate outputs when considering the efficiency and performance of the gas industry.

Two major inputs into gas transmission and distribution are the labour force involved in gas industry activities and the capital services of the pipeline system which connects producers to consumers. The labour force requires specialist skills in gas supply and engineering, as well as non specific skills in sales and administration. The services of a pipeline system depend on a wide variety of factors including pipeline diameter and length, inlet and outlet pressures and the availablity of compressor equipment to regulate operating pressures. Other factors affecting supply include the 
availability of storage capacity for seasonal and other top-up to regular supplies. The gas network functions in a fairly complex way to deliver gas to users.

The environment in which the gas industry functions varies considerably from country to country, in terms of the terrain over which gas is transported, the geographic density of customers, and their economic characteristics. While this is easily recognised, treatment of such individual circumstances can be affected by strategic considerations. Producers have an interest in stressing the uniqueness of the conditions of supply since regulatory concessions often flow from such recognition. Any such concessions may however be welfare reducing as they remove pressure on producers to improve efficiency in the absence of properly functioning competitive markets. It is sensible to adopt a cautious approach to the inclusion of environmental variables and incorporate them only when the evidence is clear.

The same cautious approach should be displayed towards potential economies of scale arguments. One of the major arguments used in favour of public ownershipis that a single producer would enjoy the benefits of large scale production. This argument is taken to justify the absence of competition for the incumbent firm. In practice, as electricity industry experience has shown, the opportunities for profitable operation at small scale are often considerable once appropriate incentives are in place.

\section{Data and Methodology}

In order to test whether changes in regulatory regime, levels of cost reducing investment and other factors have impacted on the performance of the gas industry, a frontier estimation technique is used to estimate a model with the following outputs and inputs 
Outputs: $\quad$ Gas consumption, numbers of customers

Inputs: $\quad$ Employment, pipelines

Previous work on efficiency estimation has used either stochastic frontier methods (SFA) or data envelopment analysis (DEA) techniques. SFA has a number of well known advantages - parameters of economically meaningful production functions can be estimated, scale effects can be identified, and, at least in the panel variants of this approach, individual efficiencies can be identified (Kalirajan and Shand, 1999).

On the other hand satisfactory estimates can only be obtained from relatively large data sets because the numbers of parameters are often large. At a deeper level, assumptions have to be made both about the functional form, which can be tested, and about the distribution of two types of error - the divergence of observations from the efficient frontier and the usual stochastic error term found in econometric investigation which can not. Again the stochastic models are not able to cope satisfactorily with multiproduct firms.

DEA on the other hand can cope relatively easilt with multiple outputs and inputs. In addition DEA requires minimal assumptions regarding the structure of production, and places no restriction on the functional form relating inputs to outputs. It produces detailed information on the efficiency of the unit not only relative to the efficient frontier but also to specific efficient units which can be identified as role models or comparators. It identifies slack in specific inputs so that sources of inefficiency can be analysed. A major shortcoming of DEA has until recently been its failure to deal effectively with the stochastic element of efficiency estimation. This is because DEA is based on an optimisation procedure which uses linear programming techniques to locate those producers who combine given inputs most efficiently to 
produce relevant output. These methods are sensitive to inaccuracies in input values and may yield alternative optimal solutions even when data is accurate. In the latter case, the efficiency estimates are not affected only the identification of comparators. The sensitivity to data is a more fundamental problem and places a considerable onus on care in data selection so that meaningful results can be obtained. The bulk of previous DEA studies have lacked estimates of the uncertainties surrounding individual efficiencies or the impacts of specific variables.

Recently, however, considerable advances have been made in the incorporation of uncertainty in DEA. Banker(1993) showed both that DEA is a maximum likelihood estimator of efficiency and that the estimates are consistent (i.e. the bias decreases as the sample size increases). He also suggested various tests for differences of efficiency estimates between models, including the Kolmogrov-Smirnov and t-test for nested models. These tests have been explored in some depth using Monte Carlo methods by Kittelsen (1999a) who has investigated the sensitivity of DEA estimates to the following problems

1. The property that the greater the number of restrictions placed on the model, the higher the measured efficiency values will be.

2. The known bias in DEA efficiency estimates. This bias arises because DEA indicates that certain units are $100 \%$ efficient (the comparator set) and yet the probability of a unit being exactly $100 \%$ efficient is zero. The extent of the bias, which is upward, will vary with the sample size but could be quite important for small samples.

3. The fact that the efficiency values are dependent because they are calculated in relation to the most efficient units in the data set. This makes it difficult to 
satisfy the assumption of independently distributed units which lie behind many statistical tests.

Kittelsen (1999b) finds that dependency and bias work in opposite directions with a tendency to cancel each other out. Thus it is possible to use the tests recommended by Banker. The t-test can be used when "bias is low due to large samples, low dimensionality (numbers of outputs and inputs), and inefficiency distributions that are dense at the frontier. If bias is somewhat higher, the .. KolmogrovSmirnov test is better” (p. 49).

The Kittelsen approach is a general to specific method of testing nested models (see Kittelsen, 1999a). Taking any two sets of efficiency estimates, for example one with and one without a specific input variable, the Kolmogrov-Smirnov (KS) tests the computed maximum absolute difference between the cumulated distribution function of the two sets of estimates, This is defined as $\mathrm{D}=\sup _{\mathrm{E}}\left\{\mathrm{S}_{0}(\mathrm{E})-\mathrm{S}_{1}(\mathrm{E})\right\}$ where $\mathrm{S}_{0}$ and $\mathrm{S}_{1}$ are the relevant cumulated distributions of measured efficiencies. The t-test is the familiar $\mathrm{t}$ test for the equality of group means and is distributed with $\left(\mathrm{n}_{0}+\mathrm{n}_{1}-2\right)$ degrees of freedom where $n_{0}$ and $n_{1}$ are the sizes of the samples. The KS test allows for the entire distribution of efficiencies while the t-test is a test of average impacts. It can be applied because the distribution of the sample means will be approximately normal in large samples by the central limit theorem.

That the various DEA models are nested is clearly seen from the specification of the VRS model as the general model:

$\mathrm{F}(\mathrm{y} \sigma \mathrm{VRS})=\left\{\mathrm{x}: \mathrm{y} \leq \mathrm{zM}, \mathrm{zN} \leq \mathrm{x}, \Sigma \mathrm{z}_{\mathrm{j}}=1\right\}, \mathrm{z} \gamma \nu^{\mathrm{J}}, \mathrm{y} \gamma v^{\mathrm{M}}$

The CRS model is obtained by removing the last constraint, $\Sigma \mathrm{z}_{\mathrm{j}}=1$.

$\mathrm{F}(\mathrm{y} \sigma \mathrm{CRS})=\{\mathrm{x}: \mathrm{y} \leq \mathrm{zM}, \mathrm{zN} \leq \mathrm{x}\}, \mathrm{z} \gamma v^{\mathrm{J}}, \mathrm{y} \gamma v^{\mathrm{M}}$ 
The other models are formed by successively reducing the number of ys and xs.

\section{Results}

Although data on gas production and prices is relatively abundant, very little material is available on productive inputs and costs for the purpose of international comparisons. This study uses data made available from the International Gas Union on 61 countries including developed and developing countries. Unfortunately, no split is available for the different functions carried out within the industry such as transmission, distribution or storage. Thus the results on efficiencies provide only a broad brush comparison and they will need to be supplemented by further investigated at a more disaggregated level (see Kim et al. 1999) for an example of a firm by firm comparison focusing on Japan).

Countries were included if data was available on two outputs - consumption and customer numbers; two inputs - employees and length of pipelines; and four environmental variables - share of gas in total energy (SH), growth in demand (RF), reform in terms of privatization or deregulation (Reform), and responsiveness to the European Union Gas Directive (Dir). Of the original 61 countries, some were excluded as clear outliers. These included both the USA and Russia, whose gas industries were many times the size of any other developed country. Venezuela was excluded because of concerns about the data. Ultimately, 33 countries were considered suitable for inclusion.

The most general model involved all 8 variables and an assumption of variable returns to scale. DEA efficiency estimates were made for this most general model. Then assumptions are changed and variables removed from the model either singly or in 
groups and the significance of these changes tested using the KS and t-tests described above. The null hypothesis of zero difference in efficiency measurements between the nesting and the nested model is used to justify exclusion (null hypothesis accepted) or inclusion (null hypothesis rejected) in the model. For example, the full VRS model yielded average measured DEA efficiencies of 0.869 . Nested within this model is the less restrictive constant returns to scale (CRS) model found by dropping the VRS assumption. In the CRS model with identical variables, the average efficiency is found to be 0.798 but the difference in efficiencies is not sufficient to reject the null hypothesis on both KS and t tests (see Table 1). In this instance, CRS is accepted as the basic model.

\section{\{Table 1 about here\}}

The model is then tested to see whether it is multi product by removing variable $\mathrm{Y}_{\text {CUST }}$ from the data set. This is rejected by both the KS and the t-tests but only at the $5 \%$ level. Since the two tests are conservative in tending to over-reject, $\mathrm{Y}_{\mathrm{CUST}}$ is not rtemoved. Retention of $\mathrm{Y}_{\mathrm{CUST}}$ supports the use of the multiproduct model.

Exclusion of the EU Directive is accepted by both tests as is the exclusion of the combination of Reform and the Directive. However, when RF is added to the group, both the KS and t tests are significant at the 1\% level suggesting that one out of the group is significant. The next test suggests that Reform is not the significant variable when made conditional on the Directive. On the other hand, RF conditional on Reform and the Directive is significant at the $5 \%$ level so that RF should be retained in the analysis. The SH variable, measuring the importance of gas in the energy mix, is not seen as significant and may safely be left out of the model. Finally a test of exclusion of 
Pipelines as an input is rejected at the $5 \%$ level by the KS test but is accepted by the ttest. Since the KS test is superior for small samples, it is concluded that Pipelines should be included in the model.

Although the data set is small and relates to only one year, a few conclusions can be drawn. Firstly a multi product two input production process model is not rejected by the data. Secondly, there is some evidence that efficiencies are significantly affected by rising/falling gas sales. It is not unreasonable to suppose that investment in an expanding market includes cost saving improvements which would be difficult to justify during periods when contraction occurs. On the other hand, neither of the policy-related variables seem to have had any significant effects. The EU Directive does not appear yet to have stimulated any marked productivity improvements in affected countries even though freeing of trade is one of its objectives. More importantly, the various market reforms taken as a group do not seem to have had any measurable effect either. This is probably because of the diversity of types of reform which a more sensitive set of measurements might have distinguished. Interestingly, however, high efficiency scores were obtained by some reforming countries e.g. Great Britain (GB), and these were maintained consistently across all models.

One problem with the DEA analysis so far is that it has ignored dynamic considerations. Sengupta (1995) has pointed out that the actual input output combination observed at any one time may not be optimal because adjustment processes are taking place. Thus units which appear optimal on DEA measurement may in fact prove to be inferior in the long run once factors are fully adjusted. Sengupta gives two reasons for this: “first ... capital inputs have a multiperiod dimension, since they generate outputs in future periods ... current input (DEA) thus biasing efficiency 
comparisons against capital-intensive processes. Secondly, DMUs may take more than one time period to adjust their decision variables” (Sengupta, 1994, p. 119). Further, “the DMU may be efficient for some of the time and inefficient for other times” (p. 120). Sengupta developed his ideas in the framework of a log linear production function which is not employed here. Instead the dynamic effects are tested by including a quadratic term in the change in $\mathrm{X}_{\mathrm{PIPES}}$ between 1997 and 1998 ( $\Delta \mathrm{X}_{\mathrm{PIPES}}$ ) in the production frontier.

The results are somewhat inconclusive (see Table 2). Clearly, adding a variable to the minimal DEA model improves the average efficiency result (from 0.669 to 0.796$)$ as would be expected. Neither the KS nor the t-test are passed at the $1 \%$ level of significance, although both are significant at the $5 \%$ level. This suggests that dynamic effects whilst they cannot be ignored may be difficult to isolate. It is noteworthy that including the lagged value of pipelines ( $\left.\mathrm{X}_{\mathrm{PIPES97}}\right)$ in the model did not make any difference to measured efficiencies. Lack of data prevented further analysis of dynamic effects at this stage of the research.

\section{\{Table 2 about here\}}

In general, measured efficiencies are as expected In the countries of the EU, they range from 1 (GB, Ireland and Netherlands) to 0.444 but are higher on average than for the set as a whole. The most efficient region was the Japan/Asia/Australia group with Australia, Japan, Korea, Malaysia and Thailand all achieving unit scores. By contrast the lowest efficiencies were recorded in other European countries, although Hungary, Ukraine and Poland were above average. Both Canada and Iran had above average efficiencies. (Table 3 gives the efficiency scores for all 33 counties in the 
sample.)

\section{\{Table 3 about here\}}

Marginal products (per 100 extra units of the factor) are given in the second and fifth columns of Table 4. They show higher than average marginal products (MP $\mathrm{MONS}_{\mathrm{C}}$ ) per employee in the EU, Africa, Iran and Canada. GB's marginal product by contrast is quite low, suggesting that the industry has exhausted any potential size advantages. On the other hand GB seems particularly productive in terms of customers per employee generating 33\% higher than world levels. This lends some support to the view that one of the effects of privatization has been to reduce quality (customer service) as firms have focused on cost reduction. However, Austria, Spain, Sweden, France and Germany have even higher marginal product per customer (MP ${ }_{\text {CUST }}$ )and in their cases the reason must lie elsewhere than in reform. Pipeline productivity shows a different pattern: highest marginal productivities are found for Other European countries (Bosnia, Hungary, Poland and Latvia having particularly high MP $\mathrm{CUST}_{\text {) }}$ suggesting potential for expansion in terms of new customers in these countries. In terms of sales, pipelines are most productive in North African and Iran, indicating less mature markets than in Europe and Japan/Asia/Australia (JAA).

\section{\{Table 4 about here\}}

The existence of slack in factor utilisation indicates potential for relatively painless efficiency improvements. Labour slack is particularly high in Africa and in Other European countries, areas characterised by significant state control of enterprises. By contrast labour slack is non existent throughout the EU, Canada and JAA. Slack in pipeline utilisation has a rather different implication. Spare pipeline capacity provides 
extra security in the system and can substitute for scarce storage resources. It can be helpful in the development of markets. Within the EU, France and Germany have slack pipeline capacity suggesting one of the conditions for market liberalization is met there. On the other hand, some results are difficult to interpret. Canada for example has the largest amount of slack in pipeline utilisation, and yet is reasonably efficient on other criteria.

\section{Conclusions}

Often empirical work in economics is hindered by lack of appropriate statistical information. This is particularly so in the gas industry where vital information relative to the restructuring of the industry is often unavailable because of the tradition of bilateral negotiations between government agencies and large state run companies that has dominated this sector in the past. Even in the era of privatization, the persistence of monopoly has, until recently, hindered the release of information on which yardstick evaluation of comparable activities can be made. This is one aspect of the "legacy of monopoly” as Colin Robinson has called it (Robinson, 1994, p14). This paper has made use of recently available data which provides a snapshot from which relative efficiency estimates can be made. Some results are surprising - the lack of clearly defined economies of scale, for instance. Some are less so - the inability to detect significant dynamic processes in gas production/distribution. Nevertheless the analysis does lend support to the notion that the reforms introduced in GB and intended in the rest of the EU are associated with high levels of technical efficiency, good utilization of labour and levels of underutilisation of capital sufficient to support the development of competitive markets. 


\section{References}

Banker, R. D. (1993), 'Maximum likelihood, consistency and data envelopment analysis:a statistical foundation’, Management Science, 39 (10), 1265-1273

European Commission (2000), An overview of the state of implementation of the EU Gas Directive, Brussels, Belgium: May (98/30/EC).

European Commission, (1998), Directive 98/30/EC of the European Parliament and of the Council of 22 June 1998 concerning common rules for the internal market in natural gas, Brussels, Belgium: Directive 98/30EC.

Fare, R., Grosskopf, S. and Lovell, C. A. (1994), Production Frontiers, Cambridge, UK, Cambridge University Press.

IGU (2000a), Natural Gas in 1999, Denmark: International Gas Union Press Release 23 May.

IGU (2000b), Panorama of the Gas Industry in the IGU Countries: Statistics Data 1999, Denmark: IGU.

Kalirajan, K. P. and Shand, R. T. (1999), 'Frontier production functions and technical efficiency measures’, Journal of Economic Surveys, 13 (2), 149-172.

Kim, T. Y. and Lee, J. D. (1995), 'Cost analysis of gas distribution industry with spatial variables’. Journal of Energy and Development, 20 (2), 247-269

Kim, T.-Y, Lee, J. D., Park, Y. H. and Kim, B. (1999), 'International comparisons of productivity and its determinants in the natural gas industry', Energy Economics, 21 (3), 273-293.

Kittelsen, S. A. C. (1999a), Monte Carlo simulations of DEA efficiency measures and hypothesis tests, Oslo, Norway: Memorandum 9/1999, Frisch Centre/Department of Economics, University of Oslo.

Kittelsen, S. A. C. (1999b), Stepwise DEA; Choosing variables for measuring technical efficiency in Norwegian electricity distribution, Oslo, Norway: SNF.

Newbery, D. M. (2000), Privatization, restructuring and regulation of network utilities, Cambridge, Msss., US and London, UK: MIT Press.

Price, C. W. and Weyman-Jones, T. (1996), 'Malmquist indices of productivity change in the UK gas industry before and after privatization', Applied Economics, 28 (1), 2939

Robinson, C. (1994), 'Gas: what to do after the MMC verdict', in Beasley, M. E. (ed.) Regulating Utilities: the Way Forward. London, UK: The Institute of Economic Affairs, 
pp. 1-19.

Sengupta, J. (1994), 'A model of dynamic efficiency measurement', Applied Economics Letters, 1 (7), 119-121.

Sengupta, J. (1995), Dynamics of data envelopment analysis, theory of systems efficiency, London, UK: Kluwer Academic Publishers

Yunos, J. M. and Hawdon, D. (1997), 'The efficiency of the National Electricity Board in Malaysia: an inter-country comparison using DEA', Energy Economics 19 (2), 255269 
Table 1: Tests For Gas Efficiency Model

\begin{tabular}{|c|c|c|c|c|}
\hline Ho: Exclude.. & Change in Mean & KS test & t-test & Conclusion \\
\hline VRS & 0.0710 & 0.1818 & 1.3553 & Accept CRS \\
\hline $\mathbf{Y}_{\text {CUST }}$ & 0.1580 & $0.2424^{*}$ & $2.2507 *$ & Reject exclusion \\
\hline $\mathbf{X}_{\text {DIR }}$ & 0.0200 & 0.0909 & 0.3475 & Accept exclusion \\
\hline $\mathbf{X}_{\text {REFORM+DIR }}$ & 0.0700 & 0.2121 & 1.1220 & Accept exclusion \\
\hline $\mathbf{X}_{\mathrm{RF}+\mathrm{REF}+\mathrm{DIR}}$ & 0.2180 & $0.3636 * *$ & $3.3115 * *$ & Reject exclusion \\
\hline $\mathbf{X}_{\text {REF!DIR }}$ & 0.0500 & 0.2102 & 0.7942 & Accept exclusion \\
\hline $\mathbf{X}_{\mathrm{RF} ! \mathrm{REF}}$ & 0.1480 & $0.2727 *$ & $2.0880^{*}$ & Reject exclusion \\
\hline $\mathbf{X}_{\mathrm{SH} ! \mathrm{RF}+\mathrm{REF}+\mathrm{DIR}}$ & 0.0340 & 0.1337 & 0.7488 & Accept exclusion \\
\hline $\mathbf{X}_{\text {PIPES!EMP++ }}$ & 0.1020 & $0.2424^{*}$ & 1.5212 & Reject exclusion \\
\hline Critical 5\%* & & 0.2310 & 1.6924 & \\
\hline $1 \% * *$ & & 0.2770 & 2.4448 & \\
\hline
\end{tabular}


Table 2: Tests For Dynamic Effects

\begin{tabular}{|l|c|c|c|l|}
\hline \multicolumn{1}{|c|}{ Ho: Exclude.. } & Change in Mean & KS test & t-test & Conclusion \\
\hline$\Delta$ Pipes & 0.1270 & $0.2549 *$ & $1.9747^{*}$ & Inconclusive \\
\hline $\mathbf{X}_{\text {PIPES97 }}$ & 0.0000 & 0 & 0 & Accept exclusion \\
\hline Critical $\mathbf{5 \% *}$ & & 0.2310 & 1.6924 & \\
& & 0.2770 & 2.4448 & \\
\hline
\end{tabular}


Table 3: Measured Efficiencies Using Input Oriented DEA Model

\begin{tabular}{|c|c|c|}
\hline COUNTRY & CODE & EFFICIENCY \\
\hline ALGERIA & $\mathrm{Al}$ & 0.410 \\
\hline AUSTRALIA & $\mathrm{AU}$ & 1.000 \\
\hline AUSTRIA & A & 0.497 \\
\hline BELGIUM & B & 0.764 \\
\hline BOSNIA-HERZEGOVINA & BAH & 0.567 \\
\hline BULGARIA & $\mathrm{BU}$ & 0.287 \\
\hline CANADA & C & 0.775 \\
\hline CZECH REPUBLIC & CAR & 0.408 \\
\hline DENMARK & $\mathrm{D}$ & 0.543 \\
\hline ESTONIA & $\mathrm{E}$ & 0.427 \\
\hline FINLAND & IF & 0.782 \\
\hline FRANCE & $\mathrm{F}$ & 0.627 \\
\hline GERMANY & G & 0.569 \\
\hline GREAT BRITAIN & GB & 1.000 \\
\hline HUNGARY & $\mathrm{H}$ & 0.966 \\
\hline IRAN & IRA & 0.721 \\
\hline IRELAND & I & 1.000 \\
\hline ITALY & IT & 0.622 \\
\hline JAPAN & $\mathrm{J}$ & 1.000 \\
\hline KOREA & K & 1.000 \\
\hline LATVIA & $\mathrm{L}$ & 0.585 \\
\hline LITHUANIA & LI & 0.148 \\
\hline MALAYSIA & M & 1.000 \\
\hline NETHERLANDS & $\mathrm{N}$ & 1.000 \\
\hline NEW ZEALAND & $\mathrm{NZ}$ & 0.458 \\
\hline POLAND & $\mathrm{P}$ & 0.686 \\
\hline ROMANIA & $\mathrm{R}$ & 0.310 \\
\hline SPAIN & $\mathrm{S}$ & 0.903 \\
\hline SWEDEN & SW & 0.444 \\
\hline THAILAND & $\mathrm{T}$ & 1.000 \\
\hline TUNISIA & TU. & 0.390 \\
\hline UKRAINE & $\mathrm{U}$ & 0.824 \\
\hline YUGOSLAVIA & $\mathrm{Y}$ & 0.352 \\
\hline
\end{tabular}


Table 4: Factor Productivity And Slacks

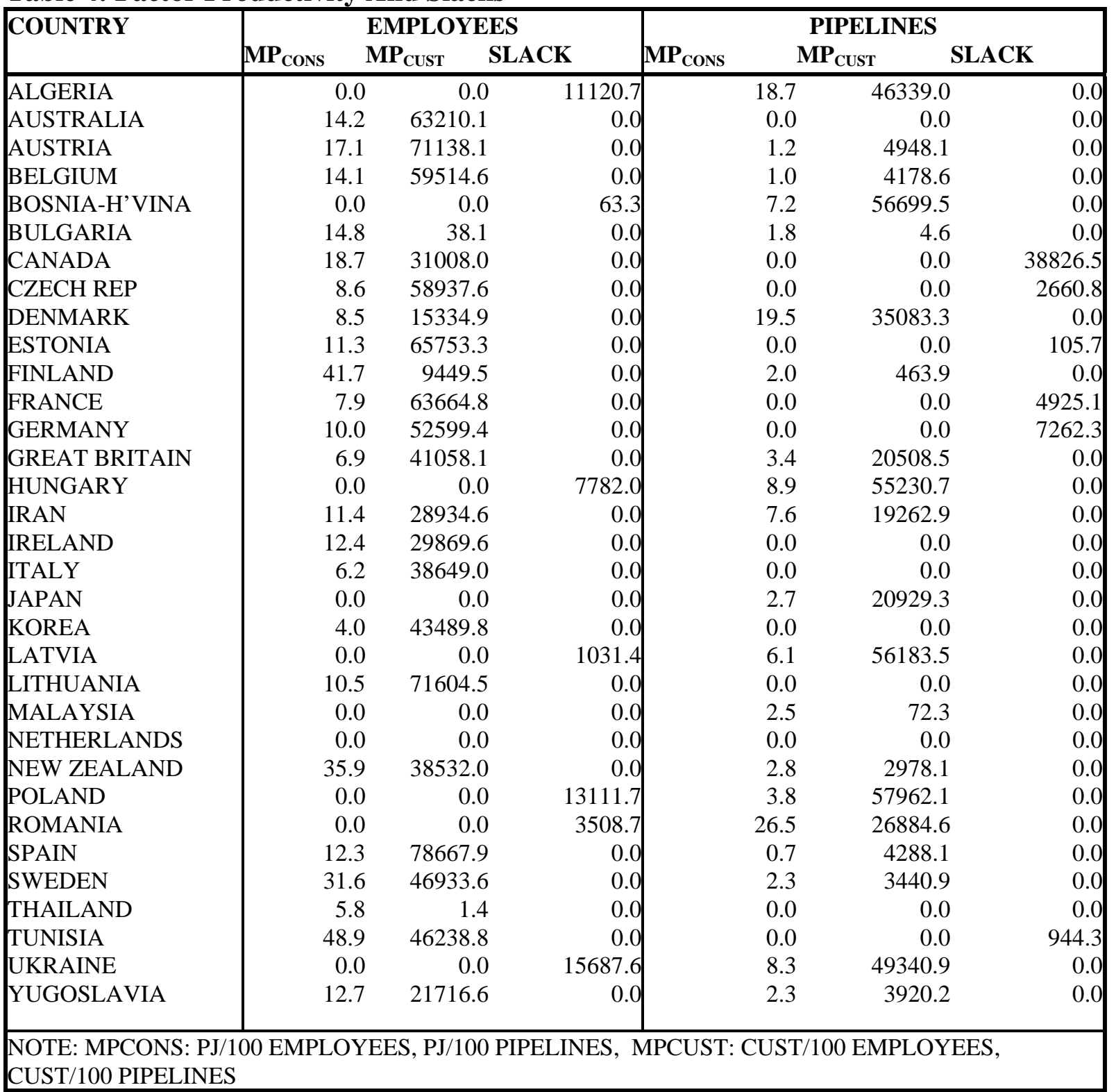


Note:

This paper may not be quoted or reproduced without permission

Surrey Energy Economics Centre (SEEC) Department of Economics University of Surrey

Guildford Surrey GU2 7XH 
SuRReY

ENERGY $_{\text {Net }}$

Economics

Discussion paper

$\mathbf{S}_{\text {ERIES }}$

\title{
For further information about SEEC please go to:
}

\author{
www.seec.surrey.ac.uk
}

